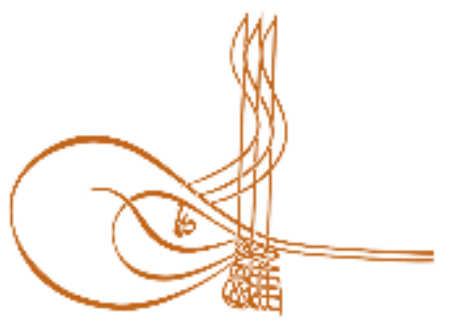

www.turkishstudies.net/turkishstudies
Turkish Studies

eISSN: $1308-2140$

Research Article / Araştırma Makalesi

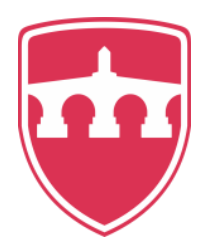

INTERNATIONAL

BALKAN

UNIVERSITY

Sponsored by IBU

\title{
Öğretmenlerin Matematik Eğitim Teorileri ve Etkinlik Tasarımı Kriterlerine İlişkin Paylaşımlarının Değerlendirilmesi
}

\author{
Evaluatıon of Teachers' Shares on Mathematics Education Theories and Activity Design Criteria
}

\author{
Elif Ertem Akbaş*
}

\begin{abstract}
In today's education systems, the educational situations in which students are active become important. Various mathematics education theories can be used in such teaching environments. Whereas, when the concepts such as mathematics education theories and scientific process skills learned in education lessons are adapted to the application stage in another course area, we can see that teachers experience various difficulties. In this sense, this study aims to evaluate the mathematics education theories used in the design of a student-centered activity from the point of view of mathematics teachers, the benefits of these theories and their sharing about the criteria of activity design. Case study, one of the qualitative research methods, was used in the study. The study group consists of 7 (5 females, 2 males) mathematics teachers who have master's education in mathematics education program and are teachers in MEB. The working group has been determined with the purposeful sampling method within the scope of easy sampling. Content analysis technique was used to analyze the data obtained through semi-structured interviews and voice recording. The findings were gathered in three main categories within the scope of the interview questions. As a result of the analysis, it has been determined that mathematics teachers have theoretically similar and general knowledge about mathematics education theories and in the design of the activity, they pay attention to the features and suitability of the teaching environment rather than the necessary stages of the activities. Within the scope of the results, it is recommended to present the necessary opportunities by taking the opinions of teachers about the change and development required in the practice in line with the relation of the activity design criteria with the mathematics education theories.
\end{abstract}

Structured Abstract: We can clearly see from the mathematics curriculum published by MEB since 2005 that the constructivist approach is based on the education systems in today's education systems and studies are carried out to make the teaching activities student-centered in this context (Ministry of National Education [MEB], 2005, 2013, 2018). In this sense, in the field of mathematics in recent years, efforts to design classes according to the constructivist theory and thus encourage students to build their own knowledge are directed towards this purpose (Zembat, 2007). One of the courses in which constructivist learning environments can be best used is mathematics (Bal and Doğanay, 2009). It can be said that it is important to encourage math teachers to actively use student-centered activities in their teaching processes. As a matter of fact, the most important dimension of education systems, apart from the theoretical and infrastructural dimensions, is the teachers who

\footnotetext{
* Dr. Öğr. Üyesi, Van Yüzüncü Y1l Üniversitesi, Eğitim Fakültesi, Matematik Eğitimi Assistant Professor, Van Yüzüncü Yıl University, Faculty of Education, Mathematics Education ORCID 0000-0002-4004-1697

eertema@gmail.com

Cite as/ Atıf: Ertem Akbaş, E. (2020). Öğretmenlerin matematik eğitim teorileri ve etkinlik tasarımı kriterlerine ilişkin paylaşımlarının değerlendirilmesi, Turkish Studies, 15(2), 959-972. https://dx.doi.org/10.29228/TurkishStudies.41979

Received/Geliş: 02 March/Mart 2020

Accepted/Kabul: 25 April/Nisan 2020

Copyright (C) MDE, Turkey
} 
assume great responsibility in practice (Ertem Akbaş et al., 2019). However, it is a situation that can be investigated whether mathematics teachers have sufficient experience in designing student-centered activities and whether they use mathematics education theories when designing these activities and to what extent they put them into practice.

In this study, it is aimed to evaluate the opinions that teachers have about the information that the mathematics education theories used in the design of a student-centered activity, about the benefits of these theories and activity design. With this purpose, in this study, it was tried to obtain information about the gap observed between theoretical knowledge and practice through teachers. 'What are the opinions of mathematics teachers about the knowledge of mathematics education theories, the importance of knowing these theories, the benefits they provide, the criteria for activity design and the methods they use in practice?' question poses the problem of this study.

In this study, case study, one of the qualitative research methods, was used. Case studies are a method that provides an opportunity to examine systematically to the respondents' responses to the questions of why and how in the context of their real life (Cohen and Manion, 1998). While selecting the study group, purposeful sampling method was used (Büyüköztürk et al., 2008). The working group consists of 7 ( 5 females, 2 males) mathematics teachers who have master's education in mathematics education program at a university located in Turkey and are teachers in MEB.

In order to reveal the feelings, thoughts, beliefs and perspectives of the teachers interviewed during the study on the topic investigated (Cohen and Manion, 1998; Y1ldırım and Şimşek, 2013); semi-structured interview method was preferred because it was possible to explain the questions in more detail, to change the order of the questions and to have the opportunity (Çepni, 2010). In order to find answers to the problem of the study, 2 different expert opinions were taken and 4 open-ended interview questions were prepared. In accordance with the opinions of the experts, 1 open-ended question was raised in terms of content validity of the questions and 3 open-ended questions were asked to the teachers. The teachers participating in the study were informed about the content of the study and approximately 10-15 minutes of face to face interviews were held with each teacher. The interviews were recorded with the permission of the teachers to avoid data loss.

During the analysis of the data, first of all, sound recordings obtained from semi-structured interviews were converted into writing. After transcribing, the data were analyzed by content analysis. After the coding phase of the data, categorization was performed within the scope of the interview questions, Analyses of coders were compared and $86 \%$ code compliance was achieved.

The findings were evaluated under three main categories as 'knowledge of mathematics education theory', 'importance and benefits of knowing mathematics education theories' and 'criteria that are considered in the design of the activity'.

It was observed that teachers related to mathematics education theories mostly express their views towards constructivist approach. According to teachers, the constructivist approach is an approach that lies at the heart of mathematics education theories. As a matter of fact, Bulut (2006) and Delil and Güleş (2007) emphasized the necessity and contributions of the use of constructivist approach in the process of teaching.

It was observed that teachers perceive the benefit of knowing mathematics education theories as managing the process correctly in the lesson. This shows that teachers do not have sufficient knowledge in practice, although they know theoretical theories of mathematics education. Similarly, Butakın and Özgen (2007) examined the effect of teaching methods in practice and emphasized that it is not sufficient to know only theoretically to understand the importance and benefits of current teaching methods.

It was concluded from the opinions of mathematics teachers that the activity design criteria were not associated with mathematics education theories. Accordingly, it has been revealed that the knowledge of mathematics education theories that teachers should utilize in effective activity design is not sufficient. However, in the related literature, emphasis was placed on planning the problems in the activities discussed in the teaching process at certain stages and designing them in accordance with the ability of students to make their own decisions (Brooks and Brooks, 1999).

As a result, it was determined that mathematics teachers have theoretically similar and general knowledge about mathematics education theories and in the design of the activity, they pay attention to the features and suitability of the teaching environment rather than the stages of the activities. The reason why

Turkish Studies, 15(2) 
teachers do not use mathematics education theories when designing their teaching situations can be explained by the fact that they did not have enough chance to practice them (Güven, 2008). However, the teachers who will teach mathematics should plan and stage the student-centered in-class activities well. In order to use these theories more frequently, lessons such as teaching practice in education programs can be increased. In addition, teachers may be given seminars with mathematics education theories and designing activities within the scope of in-service training.

Keywords: mathematics education, mathematics education theories, activity design, mathematics teachers, teacher opinions

Öz: Günümüz eğitim sistemlerinde öğrencilerin aktif olduğu öğretim durumları önem kazanmaktadır. Bu tarz öğretim ortamlarında çeşitli matematik eğitim teorilerinden yararlanılabilir. Oysa eğitim derslerinde öğrenilen matematik eğitim teorileri, bilimsel süreç becerileri gibi kavramlar bir başka ders alanında uygulama aşamasına uyarlandığında öğretmenlerin çeşitli zorluklar yaşadıklarını görmekteyiz. İşte bu anlamda bu çalışmada, matematik öğretmenlerinin bakış açısıyla öğrenci merkezli bir etkinliğin tasarımında kullanılan matematik eğitim teorileri, bu teorilerin yararları ve etkinlik tasarımı kriterleri hakkındaki görüşlerinin değerlendirilmesi amaçlanmıştır. Çalışmada nitel araştırma yöntemlerinden durum çalışması deseni kullanılmıştır. Çalışma grubunu matematik eğitimi programında yüksek lisans öğrenimi görmekte olan ve MEB'de görev yapan 5 'i kadın ve 2'si erkek olmak üzere toplam 7 matematik öğretmeni oluşturmaktadır. Çalışma grubu kolay ulaşılabilir örnekleme kapsamında amaçlı örnekleme yöntemiyle belirlenmiştir. Yarı yapılandırılmış görüşmeler ve ses kaydı ile elde edilen verilerin analizinde içerik analizi tekniği kullanılmıştır. Elde edilen bulgular görüşme soruları kapsamında üç ana kategoride toplanmıştır. Yapılan analizler sonucunda matematik öğretmenlerinin matematik eğitim teorilerine ilişkin teorik olarak benzer ve genel bilgiye sahip olduğu, etkinlik tasarımında ise etkinliklerin gerekli olan aşamalarından ziyade özelliklerine ve öğretim ortamına uygunluğuna dikkat ettiği tespit edilmiştir. Ulaşılan sonuçlar dikkate alınarak etkinlik tasarımı kriterlerinin matematik eğitim teorileriyle ilişkilendirilmesi doğrultusunda uygulamada gerekli görülen değişim ve gelişime yönelik öğretmen görüşleri alınarak gerekli olanakların sunulması önerilmektedir.

Anahtar Kelimeler: matematik eğitimi, matematik eğitim teorileri, etkinlik tasarımı, matematik öğretmenleri, öğretmen görüşleri

\section{Giriş}

"Eğitim Sistemleri"nin bireylere, yaşam süresince sergilemeleri gereken davranışları kazandırdığı aynı zamanda ülkelerin geleceğinde en etkin yönlendiriciler olduğu açıktır. Ancak bu yönlendirmeler, anında gözükmemektedir. Sonuçlarının ortaya çıkması için tasarlamada, uygulamada ve değerlendirmede belli bir sürenin geçmesi gerekmektedir. Günümüz eğitim sistemleri özelinde matematik eğitiminde yapılandırmacı anlayışın temel alındığını ve öğretim faaliyetlerinin öğrenci merkezli gerçekleşmesi için çalışmalar yapıldığını 2005'ten itibaren MEB'in yayınlamış olduğu matematik dersi öğretim programlarından açıkça görmekteyiz (Milli Eğitim Bakanlığı [MEB], 2005, 2013, 2018). Bu doğrultuda son yıllarda matematik alanında, sinıfları yapılandırmacı kurama göre tasarlama ve böylece öğrencileri kendi bilgilerini inşa etme yolunda cesaretlendirme çabaları bu amaca yöneliktir (Zembat, 2007).

Yapılandırmacı öğrenme ortamlarının en iyi kullanılabileceği derslerden biri matematiktir (Bal ve Doğanay, 2009). Dolayısıyla matematik dersinin aktif yürütücüleri olan matematik öğretmenlerinin öğretim süreçlerinde öğrenci merkezli etkinlikleri aktif bir şekilde kullanmaları yönünde teşvik edilmesinin önemli olduğu söylenebilir. Nitekim eğitim sistemlerinin kuramsal ve altyapı boyutlarının dışında kalan en önemli boyutu, uygulamada büyük sorumluluk üstlenen öğretmen ayağıdır (Ertem Akbaş vd., 2019). Sistemin verimini artırabilmek için bu ayağı oluşturan kimselerin çok iyi seçilmesi ve uluslararası standartlara uygun biçimde yetiştirilmesi zorunludur. Bununla birlikte matematik öğretmenlerinin öğrenci merkezli etkinlikleri tasarlama aşamasında yeterli deneyime sahip olup olmadıkları ve bu etkinlikleri tasarlarken matematik eğitim teorilerinden 
yararlanıp yararlanmadıkları ve bunları öğretim durumlarında ne ölçüde hayata geçirdikleri araştırılabilecek bir durum olarak karşımıza çıkmaktadır.

Derslerin daha verimli olması, öğretilmek istenen kavramın öğretmen merkezli eğitim anlayışı (örneğin sunuş yöntemi) çerçevesi dışında gerçekleşmesi için yapılan birçok çalışma ve MEB öğretim programı kaynakları (MEB, 2018) incelendiğinde öğrencilerin öğretim sürecinde aktif olmaları ve öğrenmeyi üstlenmeleri gerekliliğine vurgu yapıldığı görülmektedir (Seymen, 2017). Oysa uzun süreden bu yana eğitim sistemimizi şekillendiren ve bir türlü vazgeçemediğimiz öğretmen merkezli öğretim ortamlarının oldukça sıkıntılı olduğu açıktır. Bu durum özellikle matematik gibi temel bilimlerde yalnızca işlem yapma becerisini öne çıarmaktadır (Ertem Akbaş, 2019). Yalnızca işlem yapma becerisi gelişen öğrencilere, düşünme, usa vurma, öz güveni çoğaltma, tartışma kültürünü arttırma, iletişim becerilerini geliştirme vb. anlamlı tutum ve davranışlara yönelme şansı verilmemektedir. Oysa güncellenen eğitim sistemi yetiştirdiği bireyler için, yaşamın temel kurallarını değiştirmektedir (Çiftci ve Tatar, 2015; Kablan vd., 2013). Özetle var olan firsatlardan yararlanarak doğru ya da yanlışı irdelemeyi, projeler üreterek kazanmayı yaşamın ana dayanağı olarak sunmaktadır. Benzer şekilde matematik bilgilerinin yapılandırılmasında proje tabanlı öğrenmeye, işbirlikçi öğrenmeye, soyut kavramları somutlaştırmanın önemine dikkat çeken Uşun ve Karagöz (2009) öğrencilerin kendi deneyimlerini oluşturarak derse aktif katılımda bulunmalarının bilgilerini daha kalıcı hale getireceğine değinmiştir. Buna rağmen OECD (2017), ülkemizdeki öğrencilerin işbirlikçi problem çözme becerilerinin çok düşük olduğunu vurgulamaktadır. Öğrenciler matematiksel kavramları aktif olarak yapılandıramamaktadırlar (Wood vd., 1995). Dolayısıyla bu durumlar göz önünde bulundurulduğunda öğrencilerin aktif olduğu ortamların tasarımı önem kazanmaktadır. $\mathrm{Bu}$ tarz öğretim durumlarında öğrencilerin birbirleriyle iş birliği içerisinde olabilecekleri, hedeflenen bilgiye ulaşmaları için öğretim ortamı, araçlar (problem, etkinlik, oyun) iyi bir şekilde tasarlanmalıdır (Ertem Akbaş, 2019). Bu aşamada çeşitli matematik eğitim teorilerinden yararlanılabilir. İşte bu anlamda öğrenci merkezli etkinliklerin tasarımı ve uygulanması aşamalarında çeşitli matematik eğitim teorilerinden yararlanılabildiğini lisans öğretimi sürecinde öğrenen matematik öğretmeni görüşlerinin önemli olduğu düşünülmektedir. Bu önem paralelinde öğretmenlerin bu teoriler hakkında teorik anlamda bilgi sahibi olmasına rağmen sınıf ortamında öğrenci merkezli etkinlikleri hiç ya da nadiren tasarlayıp uygulamasının nedenlerine ve ne ölçüde uygulamaya geçirebildiklerine ilişkin sorular akla gelmektedir.

Lisans eğitim süresince alınan eğitim derslerinde çeşitli matematik eğitim teorileri hakkında bilgi sahibi olan matematik öğretmen adayları, bunları bir alanın öğretimine yönelik uygulamalar için yeterince şans bulamamaktadır (Gömleksiz, 2005). Örneğin yapılandırmacı yaklaşıma uygun öğrenme ortamlarının eğitim sürecinde yeterli düzeyde kullanılmaması nedeniyle yapılandırmacı yaklaşımın eğitim sistemine istenilen ölçüde entegre edilemediği belirtilmektedir (Richardson, 1997). Öte yandan etkinlikler nitelikli bir öğrenmenin gerçekleştirilebilmesi için çok önemlidir (Özden, 2001). Benzer olarak öğretim programına uygun olarak hazırlanan etkinliklerin doğru ve yerinde uygulanması halinde öğrenmenin daha kalıcı ve anlamlı olabileceği söylenmektedir (Bozkurt, 2012; Connolly vd., 2000; Henningsen ve Stein, 1997; Jones ve Pratt, 2006).

Eğitim derslerinde öğrenilen matematik eğitim teorileri, bilimsel süreç becerileri gibi kavramlar bir başka ders alanında uygulama aşamasına uyarlandığında öğretmenlerin çeşitli zorluklar yaşadıklarını görmekteyiz. Örneğin bir etkinlik tasarımı sürecinde teoride bu süreçler hakkında bilgi sahibi olan öğretmenler uygulama aşamasında zorluklar yaşamaktadır. Benzer şekilde Bozkurt ve Kuran (2016) öğretmenlerin, etkinliklerin zaman aldığını düşündüğüne, bu yüzden müfredatı yetiştirememe kaygısı taşıdıklarına ve dolayısı ile etkinlikleri uygulamaya sıcak bakmadıklarına vurgu yapmıştır.

Bu durumda bu çalışmada bir alanın öğretiminde, öğrenci merkezli bir etkinliğin tasarımında kullanılan matematik eğitim teorileri, bu teorilerin yararları ve etkinlik tasarımı hakkında 
öğretmenlerin sahip olduğu bilgiler ile ilgili görüşlerin değerlendirilmesi amaçlanmıştır. Bu amaç ve açıklamalar paralelinde bu çalışmada teorik bilgi ile pratik arasında gözlenen fark hakkında öğretmenler aracılı̆̆ıyla bilgi edinmeye çalışılmıştır. Bu bağlamda "Matematik öğretmenlerinin matematik eğitim teorilerine ilişkin bilgileri, bu teorileri bilmenin önemi, sağladığı yararlar, etkinlik tasarımı kriterleri ve pratikte uyguladıkları yöntemlere yönelik görüşleri nelerdir?" sorusu bu çalışmanın problemini oluşturmaktadır.

\section{Yöntem}

Bu bölümde çalışmanın modeli, çalışma grubu, veri toplama araçları ve verilerin analizi ile ilgili bilgiler sunulmuştur.

\section{Çalışmanın Modeli}

$\mathrm{Bu}$ çalışmada nitel araştırma yöntemlerinden durum çalışması deseni kullanılmıştır. Nitel araştırmalar, çalışma grubunda yer alan bireylerin anlayışlarını, duygu ve düşüncelerini, doğal ortamda gerçekçi ve bütüncül biçimde ortaya koymayı sağlaması bakımından tercih edilen bir araştırma tekniğidir (Yıldırım ve Şimşek, 2013). Nitel bir araştırma deseni olan durum çalışması ise ele alınan duruma ilişkin katılımcının neden ve nasıl sorularına verdiği cevapları gerçek yaşantıları bağlamında ayrıntılı olarak inceleyip sistematik bir biçimde açıklamaya firsat sunan bir yöntemdir (Cohen ve Manion, 1998). Bu çalışmada matematik öğretmenlerinin matematik eğitim teorilerine ilişkin bilgileri, etkinlik tasarım kriterleri ve pratikte uyguladıkları yöntemler arasındaki ilişkiye yönelik görüşleri detaylı olarak incelenmiştir. Diğer bir deyişle, öğretmenlerin matematik eğitim teorileri ve etkinlik tasarımına ilişkin bilgileri ile pratikte uyguladıkları yöntemler arasındaki ilişki öğretmenlerin bakış açısıyla "bütünsel olarak" (Yıldırım ve Şimşek, 2013) sunulmaya çalışılmıştır.

\section{Çalışma Grubu}

Çalışma grubu seçilirken çalışmanın amacı doğrultusunda kolay ulaşılabilir örnekleme kapsamında derinlemesine araştırma yapılmasına olanak sağlayan amaçlı örnekleme yöntemi kullanılmıştır (Büyüköztürk vd., 2008). Bu doğrultuda bu çalışmanın çalışma grubu 2019-2020 eğitim-öğretim yılında Türkiye'deki bir devlet üniversitesinde Matematik Eğitimi programında yüksek lisans öğrenimi görmekte olan ve MEB'de görev yapan 7 (5 kadın ve 2 erkek) matematik öğretmeninden oluşmaktadır. İlköğretim ve ortaöğretim matematik öğretmenliği programından mezun olan bu öğretmenlerden 6'sı ortaokulda, 1'i ise lisede görev yapmaktadır. Etik kurallar çerçevesinde, katılımcı öğretmenlerin isimleri Ö1, Ö2,.., Ö7 şeklinde kodlanmıştır. Ayrıca öğretmenlerin gönüllü katılımı sağlanmış olup katılımcı özellikleri Tablo 1'de sunulmuştur.

Tablo 1: Çalışmaya Katılan Öğretmenlerin Özellikleri

\begin{tabular}{cccccc}
\hline $\begin{array}{c}\text { Katılımcı } \\
\text { kodu }\end{array}$ & Cinsiyet & $\begin{array}{c}\text { Mezun olunan lise } \\
\text { türü }\end{array}$ & $\begin{array}{c}\text { Mezuniyet } \\
\text { alanı }\end{array}$ & $\begin{array}{c}\text { Görev yaptı̆̆ } \\
\text { düzey }\end{array}$ & $\begin{array}{c}\text { Meslek deneyimi } \\
\text { (yıl) }\end{array}$ \\
\hline Ö1 & Kadın & Anadolu lisesi & Sayısal & Ortaokul & 1 \\
Ö2 & Erkek & $\begin{array}{c}\text { Anadolu öğretmen } \\
\text { lisesi }\end{array}$ & Sayısal & Lise & 3 \\
Ö3 & Kadın & Anadolu lisesi & Sayısal & Ortaokul & 3 \\
Ö4 & Kadın & Anadolu lisesi & Sayısal & Ortaokul & 2 \\
Ö5 & Erkek & Anadolu lisesi & Sayısal & Ortaokul & 2 \\
Ö6 & Kadın & Düz lise & Sayısal & Ortaokul & 1 \\
Ö7 & Kadın & Anadolu lisesi & Sayısal & Ortaokul & $0-1$ \\
\hline
\end{tabular}

\section{Veri Toplama Araçları}

Çalışma kapsamında iletişim kurulan öğretmenlerin araştırılan konu hakkındaki duygu, düşünce, inanç ve bakış açılarını ortaya çıkarmak amacıyla (Cohen ve Manion, 1998; Yıldırım ve 
Şimşek, 2013) görüşme; soruları daha ayrıntılı biçimde açıklayabilme, soruların sırasını değiştirebilme, olanağ 1 (Çepni, 2010) olduğu için de yarı yapılandırılmış görüşme yöntemi tercih edilmiştir. Yarı yapılandırılmış görüşmeler ve ses kaydıyla toplanan veriler 2019 yılının güz dönemine aittir. Çalışmanın problemine cevap bulabilmek amacıyla 2 farklı uzman görüşü alınarak 4 adet açık uçlu görüşme sorusu hazırlanmıştır. Sorular uygulanmadan önce matematik eğitimi alanında doktora yapmış üç uzman görüşüne sunulmuş ve görüşme için gerekli değişiklikler yapılmıştır. Uzman görüşleri doğrultusunda soruların kapsam geçerliliği açısından 1 adet açık uçlu soru çıkarılmış ve öğretmenlere 3 adet açık uçlu soru yönlendirilmiştir. Çalışmaya katılan öğretmenlere çalışmanın içeriği ile ilgili bilgi verilmiş ve her bir öğretmenle yaklaşı 10-15 dakikalık yüzyüze görüşme yapılmıştır. Yapılan görüşmeler veri kaybı olmaması için öğretmenlerin izni ile kayıt altına alınmıştır. Çalışma kapsamında yapılan görüşmelerde öğretmenlere aşağıdaki sorular yöneltilmiştir:

- Matematik öğretmenlerinin matematik eğitim teorileri hakkında bilgileri nelerdir?

- Matematik eğitim teorilerini bilmenin önemi ve sağladığı yararlar nelerdir?

- Matematik öğretmenleri etkinlik tasarımında hangi kriterleri göz önünde bulundurmaktadir?

\section{Verilerin Analizi}

Verilerin analiz sürecinde öncelikle yarı yapılandırılmış görüşmelerden elde edilen ses kayıtları yazıya dönüştürülmüştür. Yazıya dönüştürme işlemi sonrasında veriler içerik analizi yoluyla analiz edilmiştir. İçerik analizi, birbirine benzeyen verileri belirli kavramlar ve temalar çerçevesinde bir araya getirerek okuyucunun anlayabileceği biçimde düzenleyip yorumlamayı sağlayan bir analiz tekniğidir (Büyüköztürk vd., 2008). Bu doğrultuda katılımcilardan elde edilen veriler benzerlikleri ve farklılıkları not alınarak 2 bağımsız araştırmacı tarafından kodlanmıştır. Araştırmacılar tarafindan yapılan bu kodlamada kodlamaya rehberlik edecek bir kavramsal yapı olmadığı için kodlamalara tümevarımcı bir analizle ulaşılmıştır (Strauss ve Corbin, 1990). Kodlama bittikten sonra elde edilen verilerin bir kısmı nitel araştırma konusunda deneyimli iki öğretim elemanı tarafından incelenmiş ve tekrar kodlanmıştır. Kodlayıcılara verilerin \%20'si (Forbes, 2011) seçkisiz olarak belirlenip verilmiş, kod tanım tablosuna göre tekrar kodlamaları istenmiştir. Kodlanan veriler içinde benzer cevaplar işaretlenerek verilerin analizi kolaylaştırılmıştır. Verilerin kodlama aşamasından sonra uyum düzeyleri dikkate alınarak görüşme soruları kapsamında kategorilendirme işlemi gerçekleşmiştir. Bu kategoriler, altında verilen katılımcı kodları ve frekansları ile birlikte okuyucuya anlamlı gelecek şekilde tablolaştırılmıştır.

\section{Çalışmanın Geçerliği ve Güvenirliği}

Nitel analizin güvenirliğinin sağlanması amacıyla araştırmacılarla iki kodlayıcı tarafindan yapılan kodlamalar Miles ve Huberman (1994)'ın (Güvenirlik =Görüş Birliği / Görüş Birliği + Görüş Ayrılı̆̆ı) formülü yardımıyla hesaplanmıştır. Bu formül kapsamında kodlamalardaki görüş birliğine bakıldığında tüm kodlar için araştırmacılar ile birinci kodlayıcının görüş birliği yüzdesinin 0.84 ; ikinci kodlayıcı ile 0.88 olduğu görülmüştür. Araştırmacıların iki puanlayıcı ile olan görüş birliği ortalaması ise 0.86 olarak hesaplanmıştır. Araştırmacıların kodlama güvenirliklerinin sağlanması için görüş birliği yüzdesinin \%70'in üzerinde olmasının yeterli olduğu belirtilmektedir (Miles ve Huberman, 1994). Daha sonra kodlamalardaki farklılık araştırmacıların ortak görüşü ile değerlendirilip görüş birliğine varılmıştır. Görüş birliğine varılan kodlamalar yarı yapılandırılmış görüşme sorularından elde edilen veriler kapsamında kategorilendirilmiştir. Çalışmanın güvenirliği kapsamında, verileri desteklemek ve anlamlı olmasını sağlamak amacıyla doğrudan alıntılara yer verilerek (Creswell, 2007; Patton, 2002) kategorilendirme ve kodlamaların hangi bakış açısına göre yapıldığı ortaya konulmuştur. Çalışmanın katılımcıları gönüllü öğretmenlerden seçilmiş olup görüşmeler kayıt altına alınarak çalışmanın teyit edilebilirliği (doğrulanabilirliği) sağlanmıştır. 
Çalışmanın görüşmelerinden elde edilen verilerin geçerliliğinin sağlanabilmesi için katılımcı öğretmenlerin matematik eğitim teorileri ve etkinlik tasarımına ilişkin bilgi sahibi oldukları ön görüşme ile teyit edilmiştir.

\section{Bulgular}

Bu bölümde matematik öğretmenlerinin matematik eğitim teorileri hakkındaki bilgileri ve etkinlik tasarımına ilişkin görüşlerine yönelik görüşme sorularına verdikleri cevapların analizinden elde edilen bulgular yer almaktadır. Bu doğrultuda öğretmen cevaplarından elde edilen verilerin kod ve frekansları her bir görüșme sorusu için tablolaștırılmıș ve üç kategori halinde sunulmuștur. Görüşme soruları kapsamında değerlendirilen öğretmen görüşlerine ilişkin ana kategoriler Şekil 1'de sunulmuştur.

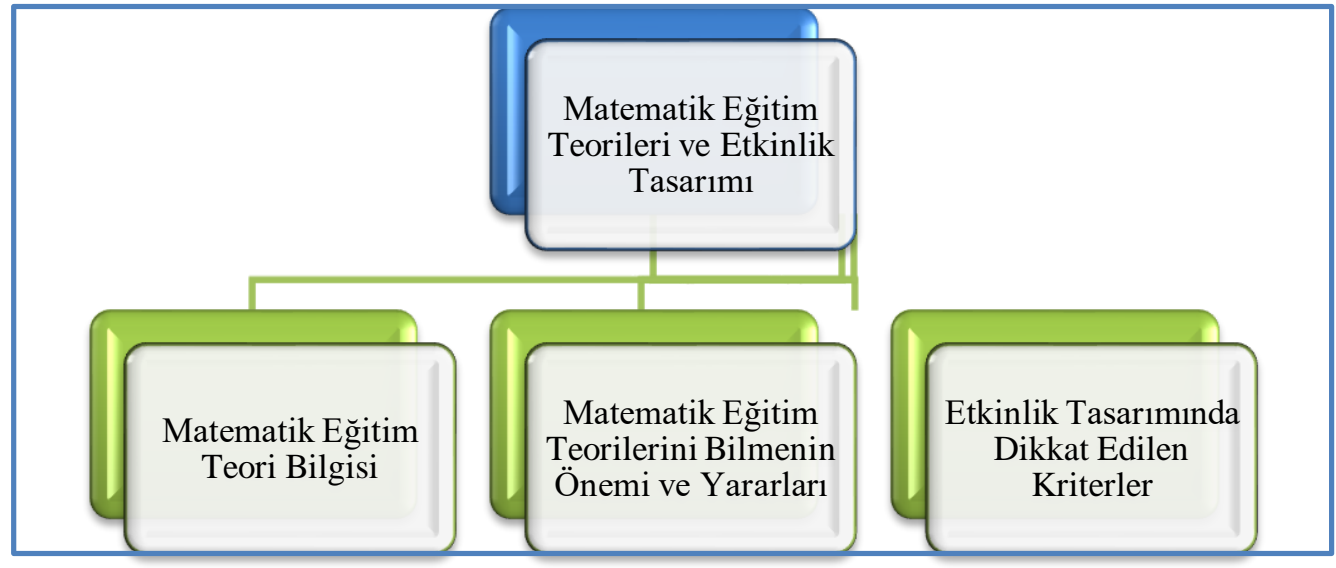

Şekil 1: Matematik Eğitim Teorileri Hakkındaki Görüşlerin Kategorilendirilmesi

Şekil 1 incelendiğinde matematik öğretmenlerinin matematik eğitim teorileri ve etkinlik tasarımı hakkındaki görüşlerinin 'matematik eğitim teori bilgisi', 'matematik eğitim teorilerini bilmenin önemi ve yararları' ve 'etkinlik tasarımında dikkat edilen kriterler' olarak üç ana kategori altında değerlendirildiği görülmektedir. Katılımcıların görüşlerinin bu kategorilere ait alt kodlamalarını gösteren bilgilere Tablo 2-3-4-5’te yer verilmiştir.

Tablo 2: Matematik Eğitim Teorileri ve Etkinlik Tasarımı Görüşlerine Ait Kategorilendirme

\begin{tabular}{ccc}
\hline Kategoriler & $\mathbf{f}^{*}$ & Katılımcı Öğretmen Kodları \\
\hline Matematik Eğitim Teori Bilgisi & 7 & Ö1, Ö2, Ö3, Ö4, Ö5, Ö6, Ö7 \\
Matematik Eğitim Teorilerini Bilmenin & 7 & Ö1, Ö2, Ö3, Ö4, Ö5, Ö6, Ö7 \\
Önemi ve Yararları & 7 & Ö1, Ö2, Ö3, Ö4, Ö5, Ö6, Ö7 \\
Etkinlik Tasarımında Dikkat Edilen Kriterler &
\end{tabular}

*Çalışmaya katılan bazı öğretmenler birden fazla görüş bildirmiştir.

Tablo 2 incelendiğinde katılımcı öğretmenlerin tamamının matematik eğitim teorileri bilgisine, matematik eğitim teorilerini bilmenin önemi ve yararlarına, etkinlik tasarlarken dikkat edilen kriterlere yönelik görüş belirttiği görülmektedir. Aşağıda bazı öğretmenlerin bu duruma ait görüşleri verilmiştir.

Ö1: Matematik teorilerine örnek olarak yapılandırmacı yaklaşım, 5E yöntemi, modelleme, oyunla öğretim, drama ile öğretim ve kavramsal ve işlemsel öğretimi verebiliriz. (Matematik eğitim teorileri bilgisi)

Ö6: Öğrencilerime etkinlik hazırlarken, sınıfın düzeyine, kazanıma uygunluğuna ve öğrencinin seviyesine dikkat ederim ayrıca etkinlikle konuya dikkat de çekilmeli. (Etkinlik tasarımında dikkat edilen kriterler) 
Ö7: Matematik eğitim teorilerini bilmek öğretmenin kazanımları öğrencinin çağına en uygun ve en başarılı bir şekilde öğretmesini sağlar. Matematik eğitim teorileri öğrencinin matematiği algılayışı, analiz ve sentez düzeyini anlamaya çalışıp matematiği öğrencinin anlamasına veya algılayamadığı noktada nedenleri ve çözüm yollarını bulmamıza yarar sağlar. (Matematik eğitim teorilerini bilmenin önemi ve yararları)

Öğretmenlerin 'Matematik ögretmenlerinin matematik ĕgitim teorileri hakkinda bilgileri nelerdir?' sorusuna ilişkin vermiş olduğu cevaplardan oluşturulan 'matematik eğitim teori bilgisi' kategorisi altında yer alan alt kodlamalar, öğretmen kodları ve frekanslar Tablo 3'te verilmiştir.

Tablo 3: Matematik Eğitim Teori Bilgisi

\begin{tabular}{ccc}
\hline Matematik Eğitim Teori Bilgisi & $\mathbf{f}^{*}$ & Katılımcı Öğretmen Kodları \\
\hline Yapılandırmacı yaklaşım & 5 & Ö1, Ö3, Ö4, Ö6, Ö7 \\
5E Yöntemi & 2 & Ö1, Ö2 \\
Modelleme & 2 & Ö1, Ö6 \\
Kavramsal ve işlemsel öğrenme & 2 & Ö1, Ö3 \\
Oyunla öğretim & 3 & Ö1, Ö2, Ö3 \\
Drama ile öğretim & 1 & Ö1 \\
Davranışçı yaklaşım & 2 & Ö5, Ö6 \\
İşbirlikçi yaklaşım & 2 & Ö2, Ö4 \\
Bilișsel yaklaşım & 3 & Ö2, Ö4, Ö6 \\
\hline
\end{tabular}

*Çalışmaya katılan bazı öğretmenler birden fazla görüş bildirmiştir.

Tablo 3 incelendiğinde katılımc1 matematik öğretmenlerinin çoğunun ( $\mathrm{f}=5)$ matematik eğitim teorilerine ilişkin yapılandırmacı yaklaşıma ilişkin bilgi sahibi olduğu görülmektedir. Ardından oyunla öğretim ve bilişsel yaklaşıma ilişkin bilgi sahibi oldukları ve görüş bildirdikleri görülmektedir. Aynı zamanda 5E yöntemi, modelleme, kavramsal ve işlemsel öğrenme, davranışçı yaklaşım, drama ile öğretim, işbirlikçi yaklaşım gibi teorilerine ilişkin de öğretmenlerin bilgi sahibi olduğu ve görüş belirtildiği görülmektedir. Matematik eğitim teorileri ile ilgili görüş belirten öğretmen frekanslarının az olması, öğretmenlerin bu teorileri eğitim-öğretim süreçlerinde yeterince uygulamamalarıyla açıklanabilir. Matematik eğitim teori bilgilerine ilişkin öğretmenlerin bazı görüşleri aşağıda verilmiştir.

Ö2: Matematik teorileri deyince aklıma, bilişsel ve işbirlikçi yaklaşımlar, 5E yöntemi ve oyunla öğretim geliyor. (Bilişsel yaklaşım, işbirlikçi yaklaşım, 5E yöntemi, oyunla öğretim)

Ö3: En başta tabi ki yapılandırıcı yaklaşım daha sonra oyunla öğretim ve kavramsal öğrenme, işlemsel öğrenme diyebiliriz. (Yapılandırıcı yaklaşım, kavramsal ve işlemsel öğrenme, oyunla öğretim)

Ö6: Örnek olarak, yapılandırıcı, davranışçı ve bilişsel yaklaşımdan bahsedebiliriz ayrıca modellemede olur. (Yapılandırıcı yaklaşım, davranış̧̧ı yaklaşım, bilişsel yaklaşım, modelleme)

Öğretmenlerin 'Matematik eğitim teorilerini bilmenin önemi ve sağladiğ l yararlar nelerdir?' sorusuna ilişkin vermiş olduğu cevaplardan oluş̧urulan 'matematik eğitim teorilerini bilmenin önemi ve yararları' kategorisi altında yer alan alt kodlamalar, öğretmen kodları ve frekanslar Tablo 4'te sunulmuştur. 
Tablo 4: Matematik Eğitim Teorilerini Bilmenin Önemi ve Yararları

\begin{tabular}{ccc}
\hline $\begin{array}{c}\text { Matematik Ĕ̆itim Teorilerini Bilmenin } \\
\text { Önemi ve Yararları }\end{array}$ & $\mathbf{f}^{*}$ & Katılımeı Öğretmen Kodları \\
\hline Uygulamalarda yol gösterici olma & 7 & Ö1, Ö2, Ö3, Ö4, Ö5, Ö6, Ö7 \\
Alan bilgisine yönelik donanımlı olma & 3 & Ö1, Ö2, Ö7 \\
Öğretim sürecini analiz edebilme & 3 & Ö1, Ö4, Ö6 \\
Bilişsel süreçleri geliştirme & 2 & Ö5, Ö7 \\
\hline
\end{tabular}

*Çalışmaya katılan bazı öğretmenler birden fazla görüş bildirmiş̧tir.

Tablo 4 incelendiğinde katılımcı matematik öğretmenlerinin tamamının matematik eğitim teorilerinin önemi ve sağladığ 1 yararlar doğrultusunda ders içi uygulamalarda yol gösterici olduğuna ilişkin görüş belirttiği görülmektedir. Bunun yanı sıra öğretmenlerden bazıları bu teorileri bilmenin alan bilgisine dair donanımlı olmalarına katkı sağladığını belirtirken, bazıları da öğretim sürecini doğru analiz edebilmek için katkı sağladığını belirtmiştir. Ayrıca diğerlerine göre daha az sayıda öğretmen ise bu teorilerin bilişsel süreçleri geliştirdiğgine dair ifadeler belirtmiştir. Matematik eğitim teorilerini bilmenin önemi ve sağladığı yararlar ile ilgili bazı öğretmen görüşleri aşağıda verilmiştir.

Ö2: Matematik öğretim yöntemlerine ve uygulamalarına hâkim olmak için bu yöntemleri içine alan teorileri bilmek önemlidir. Teorilere hâkim olmak bilim camiası tarafından doğrulanmış olgu ve gelişmelerden haberdar olmaktır. Sürekli olarak denenmiş ve geliştirilmiş eğitim olgularını kullanmak eğitim zaman, ekonomik gelişimsel olarak kazanç sağlar. (Uygulamalarda yol göstericilik, alan bilgisine yönelik donanımlı olmak)

Ö4: Var olan öğretim yaklaşımlarının analizinin daha gerçekçi yorumlamalar sağlayacaktır. Ayrıca çalışılan konuların sınırlarını belirler ve yapılan çalışmalar üzerinden yürütülecek olan çalışmaların içeriği hakkında bilgi sahibi olmamızı sağlar. Bu sınırlandırmalar içeriği daha gerçekçi kılar ve günlük hayata aktarılabilecek matematik ile ilgili somut deliller bulmamıza yardımcı olur. (Uygulamalarda yol göstericilik, öğretim sürecini analiz edebilmek)

Ö5: Öğretim etkinliklerimizi geliștirirken ve düşünce yapımızı oluştururken bu teorilerin fayda sağlayacağına inanıyorum ve günlük hayatı yordayabilme ve matematik deneyim kazanabilmemizde de yardımcı olacağını düşünüyorum. (Uygulamalarda yol göstericilik, bilişsel süreçleri geliştirir)

Öğretmenlere yöneltilen 'Matematik ögrretmenleri etkinlik tasarımında hangi kriterleri göz önünde bulundurmaktadır?' sorusuna ilişkin öğretmenlerin vermiş oldukları cevaplar doğrultusunda 'etkinlik tasarımında dikkat edilen kriterler' kategorisi altında yer alan alt kodlamalar, ögretmen kodları ve frekanslar Tablo 5 'te sunulmuştur.

Tablo 5: Etkinlik Tasarımında Dikkat Edilen Kriterler

\begin{tabular}{ccc}
\hline Etkinlik Tasarımında Dikkat Edilen Kriterler & $\mathbf{f}^{*}$ & Katılımcı Öğretmen Kodları \\
\hline Sinıf düzeyi & 4 & Ö1, Ö3, Ö4, Ö6 \\
Kazanıma uygunluk & 4 & Ö1, Ö2, Ö6, Ö7 \\
Dikkat çekici giriş & 3 & Ö1, Ö4, Ö6 \\
Sürenin uygunluğu & 3 & Ö1, Ö6, Ö7 \\
Anında dönüt düzeltme & 1 & Ö1 \\
Keşfetme & 2 & Ö1, Ö2 \\
Aktif öğrenme & 2 & Ö1, Ö5 \\
Matematiksel süreç becerileri & 1 & Ö1 \\
Hazırbulunuşluk düzeyi & 4 & Ö2, Ö3, Ö5, Ö7 \\
Cebirsel işlem yetenekleri & 1 & Ö2 \\
Yaparak yaşayarak öğrenme & 3 & Ö3, Ö4, Ö5 \\
\hline
\end{tabular}

*Çalışmaya katılan bazı öğretmenler birden fazla görüş bildirmiştir. 
Tablo 5 incelendiğinde öğretmenlerin etkinlik tasarlarken en çok sınıf düzeyine uygun olması, kazanıma uygun olması ve öğrencilerin hazırbulunuşluk düzeleri kriterlerini göz önünde bulundurdukları görülmektedir. Yine öğretmenlerin çoğu etkinliklerin dikkat çekici olması, uygulanacak zamana uygun olması ve öğrencilerin yaparak yaşayarak öğrenmelerine firsat vermesi kriterlerine dikkat etiklerini belirtmişlerdir. Ayrıca bazı öğretmenler etkinliklerin anında dönüt vermeye uygun olması, keşfederek öğretmesi, öğrencilerin aktif katılımını sağlaması, matematiksel süreç becerilerini harekete geçirmesi ve öğrencilerin cebirsel işlem becerilerine uygun olması gibi kriterlere vurgu yapmıştır. Matematik öğretmenlerinin etkinlik tasarlarken dikkat edilmesi gereken kriterlere ilişkin bazı görüşleri şu şekildedir.

Ö1: Etkinliklerimi tasarlarken; öncelikle sınıfın düzeyine ve kazanıma uygunluğuna bakarım bunların yanında etkinlik ders süresine uygun mu, öğrencinin derse katılımını sağlar mı, dikkat çeker mi, ben etkinlikte verimli bir şekilde öğrencilerime geri bildirim verebilir miyim ya da öğrenci de bu neler uyandırır veya matematiksel becerilerini nasıl etkiler bunları düşünürüm. (Sınıf düzeyi, kazanıma uygunluk, dikkat çekici giriş, sürenin uygunluğu, anında dönüt düzeltme, keşfetme, aktif öğrenme, matematiksel süreç becerileri)

Ö3: Bence en önemlisi sınıfın düzeyi, öğrencilerin hazırbulunuşluk seviyesi ve tabi ki öğrenciler yaparak yaşayarak öğrenme gerçekleştirecek mi bu etkinlikte. (Sınıf düzeyi, hazırbulunuşluk düzeyi, yaparak yaşayarak öğrenme)

Ö5: Dikkat edeceğim unsurlar öncelikle öğrencinin hazırbulunuşluğu ve şuan ki eğitim sistemimizde önemli olan aktif öğrenme yani öğrencinin katılımını sağlayan bir etkinlik olmalı bu anlamda etkinlikteki en önemli kriter gözle görülüp elle dokunabilmesi ve yaparak yaşayarak öğrenmesidir. (Hazırbulunuşluk düzeyi, aktif öğrenme, yaparak yaşayarak öğrenme)

\section{Tartışma, Sonuç ve Öneriler}

Günümüzde hedeflenen eğitim ortamları göz önünde bulundurulduğunda, öğrenci merkezli ortamların gerekliliği aşikâr bir durum olarak ortaya çıkmaktadır (Baştürk-Şahin, 2015). Bu durum beraberinde öğretici konumdaki öğretmenlerin ilgili konuya yönelik bilgi birikimlerinde ve uygulamalarında kritik bir rol almaktadır. Özel olarak matematik gibi analitik düşünme becerisinin temelini oluşturan ve dünyayı anlamamızı sağlayan temel derslerin öğretiminde bu rol daha fazla önem arz etmektedir. Dolayısıyla öğrencilerin eğitim hayatı süresince, matematiğin ve bu dersi yürütecek olan öğretmenlerin bilgi birikiminin oldukça önemli bir yeri olduğu açıtır (Ertem Akbaş vd., 2019). Bu bağlamda matematik öğretmenlerinin matematik eğitim teorileri ve etkinlik tasarım1 hakkındaki bilgileri öğrenci merkezli eğitimi ne kadar teşvik edeceğini göstermeyi sağlayacaktır. Bu nedenle bu çalışmada matematik öğretmenlerinin bakış açısıyla matematik eğitim teorileri, bu teorilerin yararları ve öğrenci merkezli bir etkinliğin tasarımı hakkında ne kadar bilgi sahibi oldukları değerlendirilmeye çalışılmıştır.

Bulgular incelendiğinde matematik eğitim teorileri ve etkinlik tasarımı hakkındaki bilgiler üç ana kategori altına toplanmıştır. Bunlar matematik eğitim teori bilgisi; matematik eğitim teorilerini bilmenin önemi ve yararları; etkinlik tasarımında dikkat edilen kriterler şeklinde belirlenmiştir. Öğretmen görüşleri doğrultusunda matematik eğitim teorileri ve etkinlik tasarımı hakkındaki bilgiler incelendiğinde matematik teori bilgisine yönelik daha genel yorumlar yapıldı̆̆ matematik eğitim teorilerini bilmenin önemi-yararları ve etkinlik tasarımında dikkat edilen kriterlere yönelik ise daha spesifik yorumlar yapıldığ görülmektedir. Bu durum spesifik olarak öğretmenlerin kendi derslerinde yer verdikleri uygulamalar doğrultusunda cevap vermiş olmaları ile ilişkilendirilebilir. Bu bağlamda öğretmenlerin alan bilgilerinin yanı sıra derslerde kullanmış oldukları yöntemlerin matematik eğitim teori bilgilerini ve etkinlik tasarımına ilişkin görüşlerini şekillendirdiği sonucuna varılabilir. Bu sonuç Iossi (2007), Shulman (1987) ve Vinson (2001) yapmış 
oldukları çalışmalarda ortaya koydukları, öğretmenlerin eğitim-öğretim bilgilerinde alan bilgilerinin yanında bu bilginin öğrencilere nasıl ifade edileceğinin önemli olduğu sonucu ile örtüşmektedir.

Matematik eğitim teorilerine ilişkin öğretmenlerin daha çok yapılandırıcı yaklaşıma yönelik görüş bildirdiği görülmüştür. Öğretmenlere göre yapılandırmacı yaklaşım, gerek bilgi ve öğrenmenin doğasını dikkate alması gerekse öğrenciyi merkeze alıp öğretimin bu doğrultuda gerçekleştirilmesi anlamında matematik eğitim teorilerinin temelinde yer alan bir yaklaşımdır. Nitekim, Bulut (2006) ve Delil ve Güleş (2007) öğretimin sürecinde yapılandırmacı yaklaşım kullanımının gerekliliğine ve katkılarına vurgu yapmıştır. Ayrıca öğretmenlerin matematik eğitim teorilerine ilişkin en çok 'yapılandırmacı anlayış’ örneğini vermelerinde, öğretmenlerin lisans eğitiminde ve MEB öğretim programlarında öğrenci merkezli öğretim durumlarıyla sıkça karşılaşmasının etkili olduğu söylenebilir. Unutulmamalıdır ki yenilenen öğretim programı (MEB, 2018) ile EBA öğrenme yönetim sistemi, yapay zekâsı, öğrenme nesnesi ambarları desteklenmiş (Ertem Akbaş, 2019) ve yapılandırmacı anlayış güçlü bir şekilde benimsenmiştir.

Öğretmenlerin matematik eğitim teorilerini bilmenin önemi ve sağladığı yararlar arasında en çok uygulamalarda yol gösterici olduğunu belirttiği görülmüş̧ür. Bunların yanında öğretmenlerin alanda donanımlı ve bilgi sahibi olmasında, öğretim sürecini analiz etmede faydalı olmasına ilişkin görüşlerin olduğu görülmüsstür. Bu görüşler doğrultusunda matematik eğitim teorilerini bilmenin yararının öğretmenler tarafından ders içerisinde süreci doğru yönetme olarak algılandığı sonucuna ulaşılabilir. Ayrıca bu sonuç öğretmenlerin matematik eğitim teorilerini teorik olarak bilmelerine karşın uygulamada yeteri kadar bilgi sahibi olmadıklarını göstermektedir. Benzer şekilde öğretim yöntemlerinin uygulamadaki etkisini inceleyen Butakın ve Özgen (2007) güncel öğretim yöntemlerinin önemini ve sağladığı yararları anlamak için sadece teorik olarak bilinmesinin yeterli olmadığını vurgulamıştır.

Öğretmenlerin etkinlik tasarımında dikkat edilmesi gereken kriterlere ilişkin görüşleri incelendiğinde çeşitli kriterlere vurgu yaptıkları görülmüştür. Öğretmenler tasarlanacak etkinliklerin en çok sınıf düzeyine, hazırbulunuşluk düzeyine ve kazanıma uygun olması gerektiğini belirtilmiştir. Bununla birlikte öğretmenler tasarımı yapılacak olan etkinliklerin dikkat çekici bir girişe sahip olması ve uygulama süresinin yeteri kadar olmasının önemine vurgu yapmışlardır. Benzer olarak bazı çalışmalarda da etkinlik tasarımı ile ilgili 'ilgi çekici, günlük yaşamla ilişkili' gibi yaklaşımlardan bahsedilmektedir (Bukova-Güzel ve Alkan, 2005). Aynı şekilde 'etkinliklerin özellikleri ve yapısı nasıl olmalıdır' sorusuna yönelik çalışmalarda da benzer sonuçlara rastlanmaktadır (Baki, 2008; Olkun ve Toluk, 2005). Bu sonuçlara ilave olarak çalışma kapsamında bazı öğretmenlerin etkinlik tasarımı kriterleri arasında yaparak yaşayarak öğrenmeyi sağlaması gerektiğine ilişkin cevaplar verdiği görülmüş̧ür. Cevaplar etkinlik tasarımında matematik eğitim teorilerinin dikkate alınmasının önemli olduğunu göstermektedir. Oysa matematik öğretmenlerinin cevapları genel olarak değerlendirildiğinde etkinlik tasarımı kriterlerinin matematik eğitim teorileri ile ilişkilendirilmediği sonucuna ulaşılmıştır. Bu sonuç öğretmenlerin uygulamada kullandıkları etkinlikleri belli bir teori ile ilişkilendirmeden sadece ders içi somut bir materyal olarak ele aldıklarını göstermektedir. Etkinliklerin, sadece ders içi somut bir materyal olarak ele alınması tasarım aşamasının kolay olmaması ile ilişkilendirilebilir. İşte bu anlamda öğretmenlerin etkili etkinlik tasarımında yararlanabilecekleri matematik eğitim teorilerinee ilişkin bilgi birikiminin gerekliliği ortaya çıkmaktadır. Nitekim ilgili literatürde öğretim sürecinde ele alınan etkinliklerin bireye uygun olmasının yanı sıra, öğretmenlerin bu etkinliklerde yer alan problemleri öğrenenler için çözmek yerine öğrencinin çözümleyebileceği ve kendi kararlarını oluşturabileceği (Brooks ve Brooks, 1999) şekilde tasarlaması gerektiğine vurgu yapılmıştır.

Sonuç olarak matematik öğretmenlerinin matematik eğitim teorilerine ilişkin teorik olarak benzer ve genel bilgiye sahip olduğu, etkinlik tasarımında ise etkinliklerin aşamalarından ziyade özelliklerine ve öğretim ortamına uygunluğuna dikkat ettiği tespit edilmiştir. Buradan öğretmenlerin 
etkinlik süreciyle ilgili kriterlere daha çok etkinliğin amacının ve özelliklerinin üzerinde durduklarını belirtmek yanlış olmayacaktır. Dolayısıyla belli bir teori çerçevesinde planlanan ve aşamaları çerçevesinde uygulanan etkinlik kriterlerine çalışma kapsamında değinen bir öğretmene rastlanmamıştır. Kısacası etkinlik tasarımı kriterleri matematik eğitim teorileriyle ilişkilendirilmemiştir. Öğretmenlerin öğretim durumlarını tasarlarken matematik eğitim teorilerini yeterince kullanmamalarının sebebi bunları uygulamada yeterince şans bulamamış olmalarıyla açıklanabilir (Güven, 2008). Teorik bilgilerin belli bir alanın öğretiminde yeterince uygulama şansı bulamayan öğretmenler (Yükseköğretim Kurumu [YÖK], 2007) daha sonraki öğretmenlik mesleği süreçlerinde zorluk yaşamaktadırlar. Unutulmamalıdır ki öğretim sürecine entegre edilen her yeni gelişimin başarıya ulaşıp, iyi sonuçlar vermesindeki en temel faktörlerinden biri öğretmenlerdir. $\mathrm{Bu}$ doğrultuda özel olarak matematik öğretimi yapacak olan öğreticilerin tasarlayacak oldukları öğrenci merkezli ders içi etkinliklerini iyi bir şekilde planlayıp, aşamalandırarak öğrenciler gibi kendi anlamlarıyla yapılandırmaları gerekir. Hedeflenen öğrenci merkezli öğretim durumlarının tasarlanması ve uygulanması aşamalarında ise büyük katkıda bulunabileceği düşünülen bu teorilerin daha sık kullanılması adına lisans eğitimi programlarında öğretmenlik uygulaması gibi derslerin arttırılması ve öğretmen adaylarının deneyim kazanmaları sağlanabilir, öğretmenlere hizmet içi eğitim kapsamında matematik eğitim teorileri ve etkinlik tasarlama ile seminer verilebilir. Ayrıca öğretmenlerden bu sürece ilişkin gerekli gördükleri değişim ve gelişime yönelik görüşler alınarak öğretmenlere çalıştıkları kurumlar tarafından gerekli olanakların sunulması sağlanabilir.

\section{Kaynakça}

Baki, A. (2008). Kuramdan uygulamaya matematik eğitimi. Ankara: Alfa yayınları.

Bal, Ö. ve Doğanay, Y. (2009). İlköğretim beşinci sınıf öğrencilerinin matematik dersinde yapılandırmacı öğrenme ortamına bakış açıları. Çukurova Üniversitesi Sosyal Bilimler Enstitüsü Dergisi, 18(2), 156-171.

Baştürk-Şahin, B.N. (2015). İlköğretim matematik öğretmenlerinin ders dokümanı hazırlama süreçlerinin incelenmesi. Yayınlanmamış yüksek lisans tezi, Uludağ Üniversitesi, Eğitim Bilimleri Enstitüsü, Bursa.

Bozkurt, A. (2012). Mathematics teachers' perceptions of mathematical activities. Education and Science, 37(166), 101-115.

Bozkurt, A. ve Kuran, K. (2016). Öğretmenlerin matematik ders kitaplarındaki etkinlikleri uygulama ve etkinlik tasarlama deneyim ve görüşlerinin incelenmesi. Ege Eğitim Dergisi, 17(2), 377398.

Brooks, M.G. ve Brooks, G.J. (1999). The courage to be constructivist. Educational Leadership, 57(3), 18-24.

Bulut, İ. (2006). Yeni ilköğretim birinci kademe programlarının uygulamadaki etkililiğinin değerlendirilmesi. Yayınlanmamış doktora tezi, Fırat Üniversitesi, Sosyal Bilimler Enstitüsü, Elazığ.

Bukova-Güzel, E. ve Alkan, H. (2005). Yeniden yapılandırılan ilköğretim programı pilot uygulamasının değerlendirilmesi. Kuram ve Uygulamada Ĕgitim Bilimleri Dergisi, 5(2), $385-420$.

Butakın, V. ve Özgen, K. (2007). Yeni ilköğretim matematik dersi öğretim programının (4. ve 5. sınıf) uygulamadaki etkililiğinin değerlendirilmesi. Dicle Üniversitesi Ziya Gökalp Eğitim Fakültesi Dergisi, (8), 82-94. 
Büyüköztürk, Ş., Çakmak Kılıç, E., Akgün, Ö.E., Karadeniz, Ş. ve Demirel, F. (2008). Bilimsel araştırma yöntemleri. (2. Baskı). Ankara: Pegem Akademi.

Cohen, L. ve Manion, L. (1998). Research methods in education. (Fifth Edition). New York: Routledge.

Connolly, T., Arkes, H. ve Hammond, K. (2000). Judgment and decision making: an interdisciplinary reader. Second edition. Cambridge University Press.

Creswell, J.W. (2007). Five qualitative approaches to inquiry. Qualitative Inquiry and Research Design: Choosing Among Five Approaches, 2, 53-80.

Çepni, S. (2010). Araştırma ve proje çalışmalarına giriş (5. Baskı). Trabzon.

Çiftci, O. ve Tatar, E. (2015). Güncellenen ortaöğretim matematik öğretim programı hakkında öğretmen görüşleri. Türk Bilgisayar ve Matematik Eğitimi Dergisi, 6(2), 285-298.

Delil, A. ve Güleş, S. (2007). Yeni ilköğretim 6. sınıf matematik programındaki geometri ve ölçme öğrenme alanlarının yapılandırmacı öğrenme yaklaşımı açısından değerlendirilmesi. Uludağ Üniversitesi Eğitim Fakültesi Dergisi, 20(1), 35-48.

Ertem Akbaş, E. (2019). The impact of EBA (Educational Informatics Network) assisted mathematics teaching in 5th grade fractions on students' achievements. Journal of Computer and Education Research, 7(13), 120-145.

Ertem Akbas, E., Cancan, M. ve Kiliç, E. (2019). Qualifications of an effective mathematics teacher from the perspectives of 5th to 8th grade secondary school students. Universal Journal of Educational Research, 7(2), 536-549.

Forbes, C.T. (2011). Preservice elementary teachers' adaptation of science curriculum materials for inquiry-based elementary science. Science Education, 95(5), 927-955.

Gömleksiz, M.N. (2005). Yeni ilköğretim programının uygulamadaki etkililiğinin değerlendirilmesi. Kuram ve Uygulamada Eğitim Bilimleri Dergisi, 5(2), 339-384.

Güven, S. (2008). Sınıf öğretmenlerinin yeni ilköğretim ders programlarının uygulanmasına ilişkin görüşleri. Milli Eğitim Dergisi, 177, 224-236.

Henningsen, M. ve Stein, M.K. (1997). Mathematical tasks and student cognition: classroombased factors that support and inhibit high-level mathematical thinking and reasoning. Journal for Research in Mathematics Education, 28(5), 524-549.

Iossi, L. (2007). Strategies for reducing math anxiety in post-secondary students. In S.M. Nielsen \& M.S. Plakhotnik (Eds.), Proceedings of The Sixth Annual College of Education Research Conference: Urban and International Education Section (pp.30-35). Miami, USA: Florida International University.

Jones, I. ve Pratt, D. (2006). Connecting the equals sign. International Journal of Computers for Mathematical Learning, 11(3), 301-325.

Kablan, Z., Baran, T. ve Hazer, Ö. (2013). İlköğretim matematik 6-8 öğretim programında hedeflenen davranışların bilişsel süreçler açısından incelenmesi. Journal of Kirsehir Education Faculty, 14(1), 347-366.

MEB, (2005). İlköğretim Matematik Dersi 6-8. Sinıflar Öğretim Programı. Ankara.

MEB, (2013). Ortaokul matematik dersi (5, 6, 7 ve 8. siniflar) öğretim programi. Ankara: Devlet Kitapları Müdürlüğü. 
MEB, (2018). Matematik dersi ögretim programı (İlkokul ve ortaokul 1, 2, 3, 4, 5, 6, 7 ve 8. sinuflar). Ankara: Milli Eğitim Bakanlığı.

Miles, M.B. ve Huberman, A.M. (1994). Qualitative data analiysis. (Second Edition). London New Delhi: Sage Publication.

OECD. (2017). Organisation for economic co-operation and development. Retrieved from http://www.oecd.org

Olkun, S. ve Toluk, Z.U. (2005). Illköğretim etkinlik temelli matematik ögretimi (3.Baskl). Ankara: An1 Yayıncilik.

Özden, Y. (2001). Öğrenme ve öğretme. Ankara: Pegem Akademi Yayınları.

Patton, M.Q. (2002). Two decades of developments in qualitative inquiry: a personal, experiential perspective. Qualitative Social Work, 1(3), 261-283.

Richardson, V. (1997). Constructivist teaching and teacher education: theory and practice. constructivist teacher education: building a world of new understandings. London: The Falmer Press.

Seymen, A. F. (2017). Y ve Z kuşak insanı özelliklerinin Milli Eğitim Bakanlığı 2014-2019 stratejik programı ve TÜBİTAK Vizyon 2023 öngörüleri ile ilişkilendirilmesi. Kent Akademisi, 10(32), 467-489.

Shulman, L.S. (1987). Knowledge and teaching: foundations of the new reform. Harvard Educational Review, 57, 1-22.

Strauss, A. ve Corbin, J. (1990). Basics of qualitative research (Vol. 15). Newbury Park, CA: Sage publications.

Uşun, S. ve Karagöz, E. (2009). İlköğretim II. kademe matematik dersi öğretim programının öğretmen görüşleri doğrultusunda değerlendirilmesi. Muğla Üniversitesi Sosyal Bilimler Enstitüsü Dergisi, 1(22), 101-116.

Wood, T., Cobb, P. ve Yackel, E. (1995). Reflections on learning and teachingmathematics in elementary schools Leslie P. Steffe ve Jerry Gale (Editör), Constructivism in Education (s 401-423). New Jersey: Lawrence Erlbaum Associates.

Vinson, B.M. (2001). A comparison of preservice teachers' mathematics anxiety before and after a methods class emphasizing manipulatives. Early Childhood Education Journal, 29(2), 8994.

Yıldırım, A. ve Şimşek, H. (2013). Sosyal bilimlerde nitel araştırma yöntemleri. (Genişletilmiş 9. Baskl). Ankara: Seçkin Yayıncılık.

Yükseköğretim Kurumu [YÖK]. (2007). Türkiye’nin yükseköğretim stratejisi. Ankara: YÖK Yayınları.

Zembat, İ. Ö. (2007). Yansıma dönüşümü, doğrudan öğretim ve yapılandırmacıllğın temel bileşenleri. Gazi Üniversitesi Gazi Ë̆itim Fakültesi Dergisi, 27(1), 195-213. 